\title{
THE ACQUISITION OF VERBAL REPETITION HABITS
}

\author{
By R. C. OLDFIELD AND O. L. ZANGWILL
}

Cambridge Psychological Laboratory

I. Introduction (pp. 12-15).

II. Method (pp. 15-16).

III. Procedure (pp. 16-18).

(1) Material (pp. 16-17).

(2) Learning (p. 17).

(3) Subjects (p. 18).

IV. Methods of analysis (pp. 18-20).

V. Results (pp. 20-22).

VI. Discussion (pp. 23-25).

(1) The normal material (pp. 23-24).

(2) The ungrammatical material (pp. 24-25).

(3) The inconsistent material (p. 25).

VII. Summary and conclusions (pp. 25-26).

References (p. 26).

\section{INTRODUCTION}

THE object of this study is an experimental investigation of the relationship between verbal repetition habits and normal recall. The problem has a certain theoretical significance in view of the sharp distinction which has sometimes been drawn between 'pure memory' on the one hand, and 'the operation of motor habit' on the other. Thus Bergson(2) envisages 'habit' as a function exclusively dependent upon specific motor mechanisms, whereas ordinary recollection he regards as a more purely and specifically psychical activity. His view has been adopted in all essentials by McDougall(6), who differs from Bergson only in the interpretation which he places upon the so-called 'pure' memory function.

Experimental data bearing directly upon this problem are somewhat meagre. Smith \& McDougall (7), it is true, have carried out experiments which appear to support Bergson's theoretical distinction. They claim that tests "of what Prof. Bergson calls 'pure memory'... show high correlation", whereas "those tests showing all the characteristics of 
habit formation... correlate with each other, but not with either member of the other group". In an examination of the recall of a prose passage, Jones \& English (5) have observed that "there is a distinct discrepancy between the ability to memorize the sense of material and to memorize the exact words". This result they consider to be antagonistic to any theory of a common memory ability, and claim that the burden of proof is thereby put " upon those who deny the Bergson-McDougall hypothesis of a difference between 'memory' and the mechanics of habit formation by contiguity association". Heymans(4), on the other hand, finds the correlation between accuracy in picture description and in the reproduction of nonsense syllables to be distinctly high, far higher, indeed, than that between descriptions of pictures and the recall of narrative prose. It is claimed that this result must inevitably reduce the plausibility of the Bergsonian theory.

More recent work by English et al.(3) once again suggests that there may be a fundamental difference between verbatim reproduction and the recall of 'substance'. These workers attempted to compare the relative facility of 'verbatim' and 'substance' learning in respect to the same task. They find that the retention curves for 'verbatim' learning show a typical Ebbinghaus decline, whereas those for 'substance' learning in most cases manifest a distinct rise. In conclusion, they suggest that learning involves "the close and inseparable cooperation of at least two processes: the one emphasized in verbatim learning and in the conditioned response, the other in 'insight', the learning of substance" (op. cit. p. 259). This latter factor they consider to be "tied up with the organized or coherent or meaningful in experience" (op. cit. p. 258) and to differ both from the learning of nonsense syllables and from the so-called 'logical' learning in which there is acquisition of coherent narrative as a repetition habit.

Bartlett(1) has also hinted at a difference between verbal habit and everyday recall. He points out that the Ebbinghaus technique of rote learning followed by verbatim recall is apt to result in the study of the acquisition and maintenance of specific repetition habits rather than in elucidation of the processes involved in normal remembering. As is well known, Bartlett's own approach involved the utilization of meaningful and relatively familiar types of material, presented under conditions analogous to those obtaining in ordinary life. He attempted, moreover, to dispense with the explicit presence of any specific "intention to remember" - a factor which had played so large and unsuspected a role in many of the earlier researches. Bartlett's results demonstrate clearly 
the extreme inadequacy of any strictly reproductive conception of memory, but appear to find satisfactory interpretation in terms of a 'schematic' theory of experimental organization adopted in conjunction with a reconstruction theory of remembering.

Bartlett does not attempt to elucidate in detail the relations between verbal habit and constructive remembering. He does, however, imply that reproductive recall is to be envisaged as dependent upon mechanisms fundamentally similar to those which he supposes to mediate high-grade constructive response. "Rote memory", he writes, "... is the most natural way of maintaining a completed 'schema' as far as possible undisturbed" (op. cit. p. 203).

It would appear to the present writers that the most significant feature in the entire controversy is the question of meaning, and its relation to memory in general. For McDougall, at all events, the formation and reproduction of a verbal habit is to be considered as depending pre-eminently upon the establishment and re-excitation of "links of mechanical association"((6), p. 336). On the other hand, everyday recollection, the 'pure memory' of Bergson, is to be attributed almost wholly to the potency of meaning-"a purely psychical product of psychic activity" 1 - as an effective determinant of reproduction. Bartlett has, however, pointed out that it is impossible to rid stimuli of meaning so long as they remain capable of arousing any human response((1), p. 4); it follows that the nonsense material so generally employed in the earlier memory experiments must acquire meaning of a somewhat specialized character. Bartlett's trenchant criticisms, moreover, suggest not only that it would be unwise to base a rigid distinction between 'memory' and 'habit' upon this factor of meaning alone, but also that an investigation into the significance of meaning for the acquisition of verbal habits might prove extremely pertinent in regard to the general problem at issue. A secondary object of our investigation will therefore consist in a preliminary assessment of the significance of meaning for learning and recall.

We may point out that in connexion with material such as a continuous prose passage, 'meaning' has at least two functionally distinct aspects. In the first place, one might take the meaning of such a prose passage to be the situation, or set of

\footnotetext{
1 Op. cit. p. 337. Compare also p. 341: "The essential difference between the rememberings of these two kinds was that in the one case meaning was at a minimum, and remembering depended almost wholly upon mechanical or neural association of the nature of habit; whereas the complex scenes and events remembered (in some instances after a single perception) were full of meaning."
} 
events, which it describes, and this will obviously include reference to the objects, persons and places mentioned, the associative significance which these elements possess for the reader, and so forth. We may call this the extrinsic meaning of the passage. In the second place, there is the formal structure of the passage, its grammatical, syntactical and logical coherence, without which it could possess no extrinsic meaning at all. This we may call its intrinsic meaning. It is the possession of intrinsic meaning that distinguishes a prose passage from a chaotic collection of words.

In view of these considerations, it is proposed to work not only with normal, meaningful, grammatical material, but also with material specially prepared so as to manifest abnormalities either in regard to extrinsic or to intrinsic meaning. In the first place, passages were included in which the meanings of words and sentences were grossly distorted through the introduction of errors and inconsistencies in grammar and syntax. In such cases, we may legitimately suppose that it is the intrinsic meaning which undergoes maximum disorganization. In the second place, a form of narrative was so constructed as to contain inconsistencies of logical and factual coherence. Thus, although the grammatical structure was left undisturbed, the events described were reduced to chaos. Apprehension and acquisition of material of this type might be expected to involve violation of habitual schemes of extrinsic meaning.

It is hoped that a comparison of the recalls obtained at various stages during the learning and forgetting of the specially constructed material may throw light upon the significance for memory of the meaning factor in both of its aspects distinguished above.

\section{MethoD}

The method of investigation was as follows: three short narrative prose passages (A, B and C) averaging about seventy words in length were used. Three versions of each passage were prepared on the following plan. One version was 'Normal' (N), another 'Ungrammatical' (U), and a third 'Inconsistent' (I). In the $\mathrm{N}$ version, the grammatical construction was correct, and the factual sequence of a straightforward nature and familiar type. In the $U$ versions wanton distortions in the grammatical form were introduced, but no further liberties taken with the plot. These distortions consisted of reversals of singular and plural and genders, and of disagreement of parts of speech. In the I versions, while the grammar was left undisturbed, far-reaching inconsistencies of factual and logical coherence were introduced. The subjects were divided into three equal groups (I, II and III). Members of each group were required to learn by heart three passages in accordance with the following scheme:

$\begin{array}{ccc}\text { Group I } & \text { Group II } & \text { Group III } \\ \text { AN } & \text { BN } & \text { CN } \\ \text { BU } & \text { CU } & \text { AU } \\ \text { CI } & \text { AI } & \text { BI }\end{array}$

At various stages during the processes of learning and forgetting they 


\section{6}

The Acquisition of Verbal Repetition Habits

were asked to recall as much of the material as they were able. The occurrence of promptings, errors and omissions were carefully recorded, and subsequently analysed in detail. By this means it was hoped to obtain information respecting the manner in which these verbal habits are built up and decay. The relevance of such data to the problem under consideration will be discussed later. The present paper is concerned only with the process of acquisition. Disintegration will be dealt with in a later paper.

\section{Procedure}

\section{(1) Material}

AN. Under a cloudless sky, he left Royston at half past seven in the morning, the lately risen summer sun beating upon his face and almost blinding him. Walking rapidly in a north-easterly direction, he reached Cambridge in time for an early lunch. By suppertime he was at Ely, and waiting only to enjoy the evening glow of gold upon the two great western towers, he went to bed.

BN. The cook was not feeling well that night and kept her own gas fire on all night, turned low admittedly, but burning continuously. Now she stated that she lighted that fire about half past nine, when she went to bed. She swears positively that she heard ten o'clock strike after she was in bed.

CN. The wall is very old-just loose stones-and as we have never repaired it, it is in some places just a pile of stones. He was three or four yards away, to my left, when I started to clamber over, carrying my gun under my right arm. I remember that he had taken his foot down and was moving back a little when suddenly a stone slipped right under my right foot,- and I lurched forward. To my horror one barrel of my gun went off.

AU. Under a cloudless skies, he leave Royston at halves past seven in a morning, the lately rose summer suns beat upon his faces, and almost blind him. Walk rapidly in a north-easterly directions, he reach Cambridge in times for a early lunches. By suppertimes he are at Ely, and waited only to enjoyed a evening glows of gold upon the two great western tower, he gone to bed.

BU. The cook were not felt well that night and keeps her own gases fire on all nights, turning low admittedly, but burned continuously. Now she state that she lighting this fires about half past nines, when she go to beds. She swore positively that she hear ten o'clock struck after she am in beds.

CU. The walls am very old-just loose stone-and as we has never repairing it, it are in some place just a piles of stones. He is three or four yard away to my left, when I starts to clambered over, carry my gun under my right arms. I remembers that he have takes his foots down, and are moved back a little when suddenly a stones slipping right under my right foots and I lurching forwards. To my horrors one barrels of my gun going off.

AI. Under a cloudy sky, he left Royston at half past one in the evening, the lately set winter sun beating down upon his face and almost blinding him. Running slowly in a south-easterly direction, he reached Cambridge too late for an early tea. By 
lunch-time he was not at Ely, and not waiting only to enjoy the midnight glow of gold upon the three small eastern towers, he rose from bed.

BI. The cook was not feeling well that night and kept her own gas fire off all night, turned high admittedly, but burning continuously. Now she stated that she lighted that fire about half past eleven when she went to bed. She swears positively that she heard nine o'clock strike after she was in bed.

CI. The wall is very new-just loose stones-and as we have always repaired it, it is in every place just a pile of stones. He was three or four hundred yards away, to my left, when I stopped clambering under, carrying my gun under my right leg. I forget that he had taken his foot up and was moving back a little when gradually a stone slipped right under my right hand and I lurched backwards. To my joy three barrels of my gun went off.

\section{(2) Learning}

The learning of all three passages by each subject was, wherever possible, accomplished in one sitting. The order of learning was $\mathrm{N}$ first, followed by $\mathrm{U}$ and then I. A brief pause occupied with conversation was allowed between each passage and the next, and at such other times as seemed desirable. The subject was handed a typed copy of the passage to be learnt, and instructed to read it through carefully three times at his own normal speed with a view to getting it by heart, and to hand the paper back when he had finished. He was then asked to repeat orally as much of the passage as he was able, and told that he would be prompted and corrected wherever necessary. At the end of this attempt the paper was returned to him with the request to read it through again from one to three times according to the degree of proficiency shown in the repetition. This procedure was repeated until the number of errors and prompts had reached an extremely low level. One experimenter directed the activities of the subject, prompting and correcting where necessary, whilst the other recorded, in as great a detail as was possible using longhand, errors, prompts and times taken in learning and repetition. To ensure as far as possible uniformity of method in recording, the experimenters occupied the same roles throughout.

While the number of readings demanded before each repetition (except the first) was within narrow limits variable and adjusted to the rate of progress of each individual, it was decided that in view of such individual variability, proportional progress from one trial to the next would be approximately the same for all subjects. The actual number of times that the subject read through the material before each repetition was therefore, for present purposes, neglected.

Brit. J. Psychol. xxıx, 1 


\section{(3) Subjects}

Fifteen subjects learnt the material. These were arbitrarily divided into three groups of five. Among these were three professional actors well experienced in memorizing prose material, a lecturer and three research workers in psychology, an anthropologist, and a number of undergraduates. Of the fifteen subjects, four were women.

\section{Methods of analysis}

In view of Bartlett's results, it was decided that some such classification of errors as the following would be best suited to the purpose in hand:

(1) Prompts.

(2) Omissions.

(3) Synonyms and Equivalents.

(4) Factual Conventionalizations.

(5) Verbal Rationalizations.

(6) Ungrammatical Constructions.

(7) Constructive Importations, Additions and Verbal Transpositions.

(8) Unclassified.

The complexity of the reproductive processes is such that these categories cannot be regarded as being strictly segregated one from another, and we believe that a rigid system of classification is apt to result in theoretical artificiality. The following broad definitions should serve adequately to illustrate this system of classification:

(1) Prompts. In cases where a subject apparently found himself totally unable to begin or continue with his repetition, one or two of the required words were spoken by the experimenter. If the subject remained unable to continue, further words were given until the subject was able to proceed unaided, each such interruption by the experimenter constituting a further prompt for the purposes of scoring.

(2) Omissions. The following types of error were classified as constituting a single omission: (a) Omission of single parts of speech not involving interruption of delivery or any considerable distortion of the original meaning. Instances of omission that caused a significant change of meaning were scored not only as omissions but also as rationalization or conventionalization as the case might be. (b) Groups of words constituting relatively unified meaningful points. Thus the omission of a 
subordinate clause did not count according to the number of words it contained but according to the number of such meaningful points.

Examples. (a) "... when a stone slipped..." for "... when suddenly a stone slipped..." (simple omission).

(b) “. . carrying my gun under my right arm..." entirely omitted (scored as two omissions).

(3) Synonyms and Equivalents. This category comprises not only synonyms in the strictly semantic sense, but also a number of verbal transformations which in that particular context could be regarded as subserving the subject's intention to formulate a correct apprehension of the original meaning. The text of the original and the subject's formulation could in such instances be regarded as psychologically equivalent.

Examples. "...walking swiftly..." for “...walking rapidly..." (strictly semantic type). “. . a step backwards..." for “... back a little..." (equivalent type).

(4) Factual Conventionalization. Bartlett has defined rationalization as reduction of material to a form that can be readily and satisfyingly dealt with by the subject((1), pp. 93-4). Where such reduction involves translation into a form that is "socially acceptable" (and indeed "socially determined") the process has been termed conventionalization. In the present circumstances, such conventionalization is shown by the manner in which descriptions of events and situations regarded as unfamiliar or unusual by the subject are translated into a form more in keeping with his everyday experience and social setting. The following types of error were therefore classified as factual conventionalizations:

Examples. "... by lunch time he was at Ely..." for "... by lunch time he was not at Ely..." (scored also as an omission). ". . .one barrel of my gun went off..." for "... three barrels of my gun went off...".

(5) Verbal Rationalization. ${ }^{1}$ This category comprises only certain types of error made in the repetition of the ungrammatical passages. Typically this involved simple grammatical correction. Such correction was generally confined to alteration' of the inflexion of single words, but might on occasion manifest itself in widespread change of grammar and sequence.

Examples. ". . a pile of stones..." for "... a piles of stones..." (simple type). "... under my feet..." for "... under my right foots..." (complex type).

1 This term has been used in a somewhat different and more comprehensive sense by Bartlett((1), p. 93). 
(6) Ungrammatical Constructions. In the repetition of the ungrammatical passages, subjects were apt to introduce grammatical errors at. places where none had existed in the original material.

Example. "...he am..." for" "...he is...".

(7) Constructive Importations, Additions, and Verbal Transpositions. This category included a number of closely related types of essentially constructive change.

Examples. "...at half past nine..." for "...about half past nine...". "... Now the cook was not feeling well..." for "... The cook was not feeling well...". "...heard the clock strike ten..." for "... heard ten o'clock strike...".

(8) Unclassified. A very small number of errors occurred which could not readily be placed in any of the above classes. These were minor changes resulting from the operation of the general constructive tendency to organize material into a form satisfactory to the subject.

\section{Results}

Table I shows the actual number of each type of error made at each repetition for each of the three types of material. Table II shows the distribution of each type of error expressed as a percentage of the total errors made in each type of material. Table III gives for each type of material the total of changes other than those found only in the Ungrammatical Material, that is to say Omissions, Transpositions, etc., Synonyms, and Factual Conventionalizations. Fig. 1 shows the manner in which Prompts become eliminated throughout the learning process. Fig. 2 shows the elimination of Factual Conventionalizations, and Fig. 3 that of the total constructive changes. Fig. 4 demonstrates the elimination of Verbal Rationalizations in the case of the Ungrammatical Material.

It will be noticed from Table I that elimination of Omissions proceeds in an essentially similar way for all three types of material. In the case of Transpositions it can be seen that, as compared with the other two classes of material, a great many errors of this type occur in the case of the normal material at all except the final stages of the learning process. On the other hand, the elimination of the type of error which we have called 'synonymous' progresses in a somewhat irregular manner. At the first repetition, however, a greater number by about $40 \%$ of this type of error occurs in the inconsistent material than in the other two types. Some striking effects are noticeable by a study of the values obtained 
for Factual Conventionalization at the various stages in the learning process (see Fig. 2). It must be borne in mind, however, that our results are insufficient to admit of conclusions of a statistically valid nature. Two points are of special interest in connexion with the elimination of conventionalization. First, the high initial level and very rapid fall of

Table I. Number of classified errors made at each repetition for each type of material

\begin{tabular}{|c|c|c|c|c|c|c|c|c|c|c|c|c|}
\hline \multirow[b]{2}{*}{ Category } & \multirow[b]{2}{*}{ Material } & \multicolumn{10}{|c|}{ Trial } & \multirow[b]{2}{*}{ Total } \\
\hline & & 1 & 2 & 3 & 4 & 5 & 6 & 7 & 8 & 9 & 10 & \\
\hline Omissions & $\begin{array}{l}\mathrm{N} \\
\mathbf{U} \\
\mathbf{I}\end{array}$ & $\begin{array}{l}37 \\
37 \\
29\end{array}$ & $\begin{array}{l}18 \\
32 \\
19\end{array}$ & $\begin{array}{l}14 \\
16 \\
17\end{array}$ & $\begin{array}{r}11 \\
16 \\
3\end{array}$ & $\begin{array}{l}6 \\
7 \\
4\end{array}$ & $\begin{array}{l}9 \\
4 \\
1\end{array}$ & $\begin{array}{l}1 \\
2 \\
2\end{array}$ & $\begin{array}{l}0 \\
2 \\
0\end{array}$ & $\underline{-}$ & $\underline{-1}$ & $\begin{array}{r}96 \\
119 \\
75\end{array}$ \\
\hline Transpositions, etc. & $\begin{array}{l}\mathbf{N} \\
\mathrm{U} \\
\mathbf{I}\end{array}$ & $\begin{array}{l}55 \\
34 \\
\mathbf{4 4}\end{array}$ & $\begin{array}{l}46 \\
37 \\
24\end{array}$ & $\begin{array}{l}43 \\
20 \\
17\end{array}$ & $\begin{array}{l}31 \\
15 \\
11\end{array}$ & $\begin{array}{r}22 \\
7 \\
9\end{array}$ & $\begin{array}{r}11 \\
8 \\
2\end{array}$ & $\begin{array}{l}3 \\
\tilde{5} \\
1\end{array}$ & $\begin{array}{l}6 \\
3 \\
2\end{array}$ & $\underline{1}$ & $\underline{1}$ & $\begin{array}{l}217 \\
131 \\
110\end{array}$ \\
\hline Synonyms & $\begin{array}{l}\mathrm{N} \\
\mathrm{U} \\
\mathrm{I}\end{array}$ & $\begin{array}{l}5 \\
5 \\
8\end{array}$ & $\begin{array}{l}6 \\
4 \\
3\end{array}$ & $\begin{array}{l}3 \\
5 \\
3\end{array}$ & $\begin{array}{l}5 \\
1 \\
3\end{array}$ & $\begin{array}{l}3 \\
2 \\
3\end{array}$ & $\begin{array}{l}2 \\
2 \\
0\end{array}$ & $\underline{-1}$ & - & $\overline{1}$ & $\underline{0}$ & $\begin{array}{l}24 \\
22 \\
20\end{array}$ \\
\hline Conventionalization & $\begin{array}{l}\mathbf{N} \\
\mathbf{U} \\
\mathbf{I}\end{array}$ & $\begin{array}{r}10 \\
6 \\
19\end{array}$ & $\begin{array}{r}7 \\
12 \\
11\end{array}$ & $\begin{array}{l}7 \\
5 \\
4\end{array}$ & $\begin{array}{l}4 \\
4 \\
3\end{array}$ & $\begin{array}{l}5 \\
0 \\
4\end{array}$ & $\begin{array}{l}0 \\
1 \\
0\end{array}$ & $\underline{-}$ & $\underline{-}$ & $\frac{1}{-}$ & 二 & $\begin{array}{l}34 \\
28 \\
41\end{array}$ \\
\hline Rationalization & $\mathrm{U}$ & 78 & 57 & 40 & 30 & 20 & 15 & 8 & 10 & 6 & 4 & 268 \\
\hline $\begin{array}{l}\text { Ungrammatical } \\
\text { Construction }\end{array}$ & $\mathbf{U}$ & 14 & 6 & 2 & 3 & 4 & 2 & 0 & 0 & 0 & 0 & 31 \\
\hline
\end{tabular}

Table II. Percentages of total errors falling under each category for each type of material

\begin{tabular}{ccccccc}
\multicolumn{7}{c}{ each type of material } \\
Group & Omissions & $\begin{array}{c}\text { Trans- } \\
\text { positions }\end{array}$ & $\begin{array}{c}\text { Synonyms } \\
\text { Convention- } \\
\text { alization }\end{array}$ & $\begin{array}{c}\text { Rationali- } \\
\text { zation }\end{array}$ & $\begin{array}{c}\text { Ungram- } \\
\text { matical } \\
\text { Construction }\end{array}$ \\
N & $25 \cdot 9$ & $58 \cdot 6$ & $6 \cdot 5$ & $9 \cdot 2$ & - & - \\
U & $19 \cdot 9$ & $21 \cdot 9$ & $3 \cdot 7$ & $4 \cdot 7$ & $44 \cdot 7$ & $5 \cdot 2$ \\
I & $30 \cdot 5$ & $44 \cdot 7$ & $8 \cdot 1$ & $16 \cdot 7$ & - & -
\end{tabular}

Table III. Total changes for each type of material

$\overbrace{\begin{array}{c}\mathrm{N} \\ 371\end{array}} \begin{array}{cc}\mathrm{U} & \mathrm{I} \\ 300 & 246\end{array}$

errors of this type in the inconsistent versions: secondly, the low initial level in the ungrammatical material followed by a $100 \%$ increase at the second trial. It is interesting to note that in the total constructive changes, whereas an average fall of about $35 \%$ is recorded in the cases of the normal and inconsistent material between the first and second trials, the corresponding value for the ungrammatical material remains almost constant, indeed it shows a slight rise (Fig. 3). 


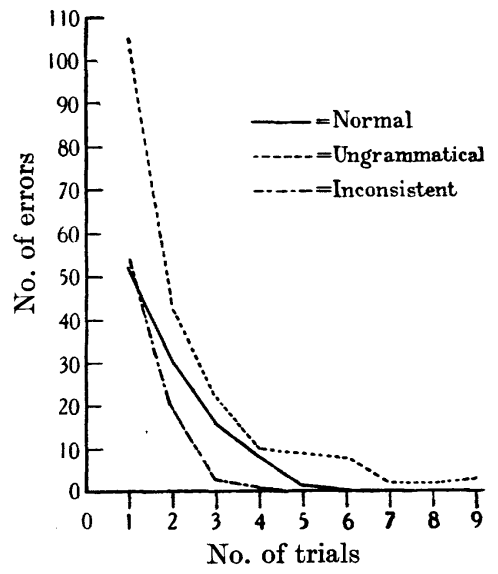

Fig. 1. Prompts.

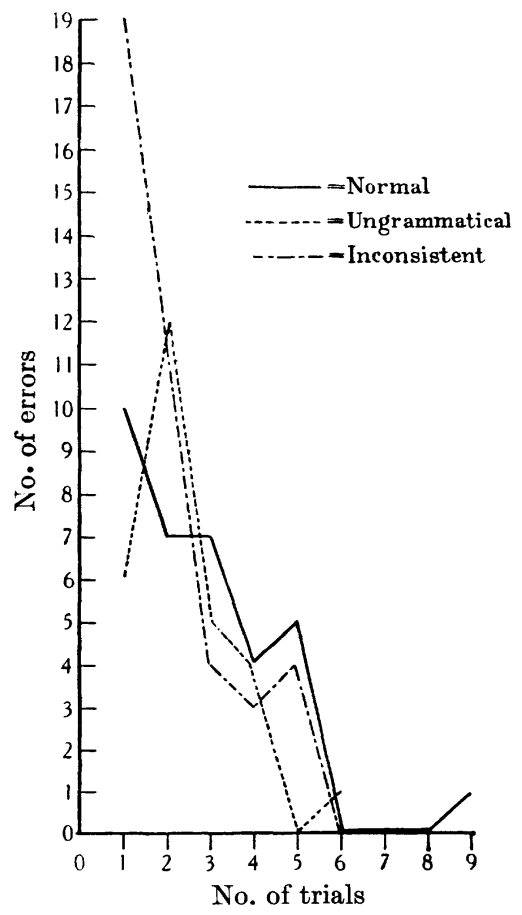

Fig. 2. Factual Conventionalization.

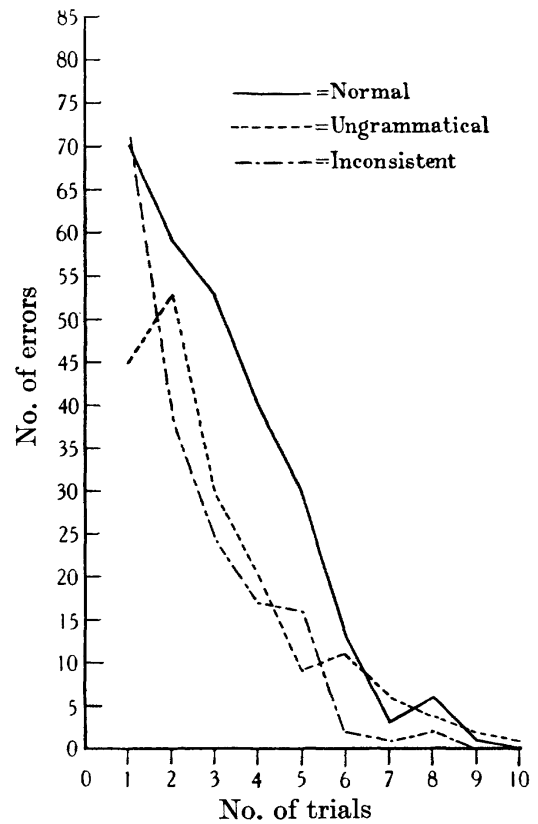

Fig. 3. Total "constructive" changes.

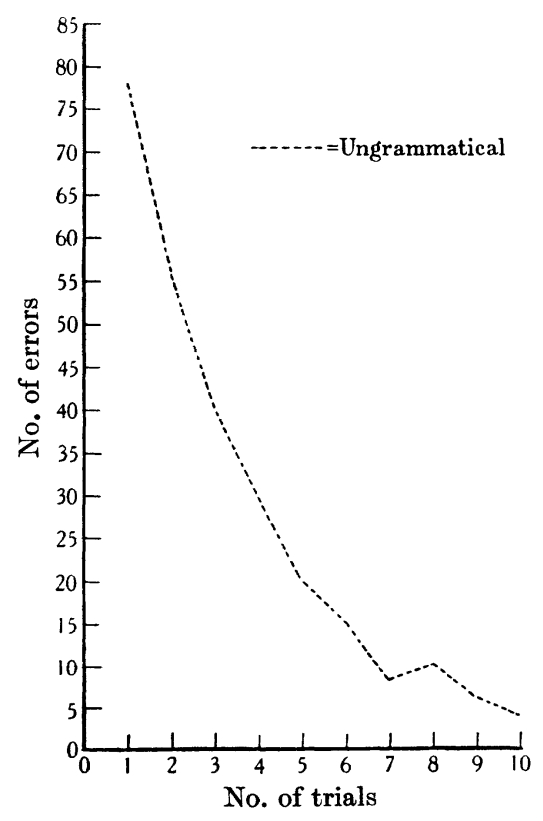

Fig. 4. Rationalization. 


\section{Discussion}

\section{(1) The normal material}

The early repetitions possess an essentially constructive character. Many errors that occur will be seen to fall into categories that have been held to represent constructive types of change. As learning proceeds, errors of this type become progressively eliminated until a stage of almost literal reproduction is attained. From the nature of the curves, this transition has every appearance of being a continuous process. One may therefore suggest that with material of this type and under the conditions employed, the constructiveness of recall diminishes progressively during learning. The earliest repetitions indicate that a general scheme of the material, together with a few specific details, is all that is retained. Owing to our conditions of recall, these few details only can be accurately reproduced, but by the aid of prompts a continuous though as a rule extremely constructive version is rendered. One may suppose that with increase in the organization of the 'schema', 1 reproduction becomes more literal, and constructive tendencies operate to a much smaller extent.

From this account it may be concluded that verbal repetition habits are of a fundamentally 'schematic' nature. Interpretation on the basis of the earlier type of trace theory would require that improvement in performance should consist only in the progressive addition of detail at each stage, and in progressively greater availability of already acquired detail for the purposes of recall. A trace theory cannot account for the early formation of a general scheme. Our experiments have shown that the sequence of events involves at least the following stages: First, the formation of a very general 'scheme' with retention of 'dominant' 2 detail. At this stage, constructiveness operates in virtue of the existence of 'scheme' and detail, which, moreover, constitute the very material upon which constructive processes work. After a few more repetitions, it would appear that the 'scheme' becomes more articulated, comprising within itself more interrelated detail, and the essentially constructive character of remembering is consequently much less in evidence. At the final stages, a degree of organization of the scheme is attained sufficient

\footnotetext{
1 Bartlett's definition of 'schema' as "an active organization of past reactions, or of past experiences, which must always be supposed to be operating in any well-adapted organic response" $((1)$, p. 201) will be provisionally accepted. A more detailed discussion of this concept will be presented in a forthcoming paper by the present writers.

2 For explanation of the use of this term, see Bartlett((1), pp. 31-2).
} 
to permit of almost literal reproduction. This may, so far as our evidence goes, be interpreted in either of two ways. In the first place one might regard this verbatim reproduction as representing the autonomous functioning of a well-organized 'scheme', constructive processes intervening only in the event of a breakdown of the reproductive mechanism. But, on the other hand, it might be supposed that the 'schematic' material available for constructive remembering is so well organized and differentiated that reconstruction can be identified with literal reproduction. Whichever of these alternative views may be correct, there can be no doubt that the acquisition of verbal repetition habits is a process involving the establishment, differentiation and operation of schematic mechanisms. This is in fact the view that Bartlett himself appears to adopt, ${ }^{1}$ although, as has previously been pointed out, the actual relation between verbal repetition habits and normal remembering has not been worked out by him in detail.

\section{(2) The ungrammatical material}

From analysis of recall of the ungrammatical material the following facts have emerged: (1) Grammatical Rationalizations constitute a very high percentage of the total errors made. (2) The absolute number of errors falling under what we have termed constructive categories is lower by $40 \%$ than in the normal passages. (3) During the earlier trials constructive errors fall off at a very much lower rate than in either the normal or the inconsistent material. In the case of Conventionalizations, in fact, there is a rise amounting to $100 \%$ between the first and second trials. (4) $5 \%$ of the total errors in this kind of material are of the type called Ungrammatical Constructions. (5) The number of Prompts is very much larger in the ungrammatical material than in either of the other two types.

These facts indicate that the process of acquisition of ungrammatical material as a repetition habit takes the following course: First, it is unlikely that any but the very vaguest scheme is in operation at the first repetition. This is suggested by the high value for Prompts. A few phrases, generally characterized by dominant detail, can be recalled, though often in a strongly rationalized fashion. Nevertheless, an awareness of the ungrammatical nature of the original material must form part

\footnotetext{
1 See Bartlett(1), p. 205. Prof. Bartlett has, however, pointed out to us that a highly articulated and differentiated scheme might perhaps be identified with an organized system of traces. This possibility will be discussed by the present writers in a subsequent communication.
} 
of this scheme, since Ungrammatical Constructions are very much in evidence at the first repetition. At the second repetition, a more coherent version of the original material is obtained; Prompts and Rationalizations diminish, and recall has that constructive character which typified the first repetition of the normal material. Differentiation and organization of the 'scheme' then takes place in a manner similar to that which we have already discussed. The lower level of constructive changes found in material of this type probably indicates that some at least of the subjects adopted a rather different method of learning this material as compared with normal. It would seem that intrinsic meaning is of considerable importance in the early stages of 'scheme' formation, and must be taken into account in any theory of remembering.

\section{(3) The inconsistent material}

The following are the principal facts relating to the recall of the inconsistent material: (1) The total of errors is lower than in either of the other two types of material. (2) The initial level both of Factual Conventionalizations and of synonymous change is higher than are the corresponding values for the other two types of material.

The first of these two results may well be due to the influence of practice in rote learning, since the order in which the passages were learnt was always the same, namely (1) Normal, (2) Ungrammatical, and (3) Inconsistent. As is to be expected, material incorporating factual and logical inconsistencies provides opportunity for widespread operation of the particular type of constructive change represented by conventionalization and equivalent synonyms. It can safely be concluded that the peculiar character of the material does not interfere with the process of scheme formation. Indeed certain bizarre elements may actually function as dominant and facilitate recall. It would seem that disturbance of the mode of extrinsic meaning, in a direction divergent from the habitual, exercises little effect upon the process of scheme formation.

\section{SUMmary AND CONCLUSIONS}

An attempt has been made to study the processes involved in the acquisition of verbal repetition habits. Three types of narrative prose material, namely Normal, Ungrammatical, and Inconsistent, were successfully learnt by fifteen subjects. At specified stages during the learning, repetitions were obtained, prompts and corrections being given where necessary, and all errors being recorded and subsequently analysed. 
The results appear to indicate that the acquisition of a verbal repetition habit cannot satisfactorily be accounted for on the basis of the older type of trace theory. An alternative interpretation has been put forward based upon Bartlett's conception of 'schema'. On such a view it is suggested that the first stage of learning is the formation of a very general scheme which incorporates a certain amount of dominant detail. Further learning consists in the progressive differentiation and organization of this scheme until finally it becomes capable of mediating literal recall of the material learnt.

The writers would like to express their sincere appreciation to Prof. Bartlett for his many suggestions, and for a great deal of invaluable criticism.

\section{REFERENCES}

(1) Bartlett, F. C. (1932). Remembering. Cambridge University Press.

(2) Bergson, H. (1911). Matter and Memory. London: George Allen and Unwin, Ltd.

(3) English, H. B., Welborn, E. L. \& Killian, C. D. (1934). "Studies in substance memorization." J. Gen. Psychol. XI, 233-60.

(4) Heymans, G. (1913). "Les 'deux mémoires' de M. Bergson." Ann. Psychol. $\mathrm{XIX}, 66-74$.

(5) Jones, M. G. \& English, H. B. (1926). "Notional v. rote memory." Amer. J. Psychol. xxxvII, 602-3.

(6) McDougall, WM. (1911). Body and Mind. London: Methuen.

(7) Sмith, M. \& McDodgall, WM. (1919). "Some experiments in learning and retention." This Journal, x, 199-209.

(Manuscript received 4 March 1937) 